\title{
Priority ranking for energy resources in Turkey and investment planning for renewable energy resources
}

\author{
Mehmet Emin Baysal ${ }^{1}$. Nazlı Ceren Çetin ${ }^{2}$
}

Received: 17 April 2017 / Accepted: 24 May 2018 / Published online: 4 June 2018

(c) The Author(s) 2018

\begin{abstract}
Energy has been an essential factor in determining the governments' policies. The countries had to produce their own energy to decrease dependency on external resources. That also provided to gain a great importance on investment on power plants. In this study, a multi-objective Mixed-Integer Linear Programming (MILP) model synchronously optimizing five targets determined as decreasing carbon dioxide $\left(\mathrm{CO}_{2}\right)$ emission, increasing power consumption, increasing power plants, increasing energy generation and installed capacity was used. In described model, it was solved by considering renewable power plants in Turkey and fossil fuel-based power plants having most share in Turkey. By trying to minimize deviation values of Turkey's 2023 targets, it aimed to determine which power plants need to be increased. To determine the priorities of these targets, Ranking Approach for fuzzy numbers by Liou and Wang (1992) was used. Besides, Fuzzy Analytic Hierarchy Process (AHP) was used to prioritize investment planning of renewable power plants in Turkey and five different kinds of power plants under the visual pollution criteria based on amount of $\mathrm{CO}_{2}$ emission released, environmental damage, capital costs, space requirement and provided employment were evaluated.
\end{abstract}

Keywords Fuzzy Analytic Hierarchy Process · Power plants · Goal programming · Turkey’s 2023 targets · Renewable energy

\section{Introduction}

Energy is one of the most essential factors for a country's social welfare and sustainable development. Recently, population growth, industry development, and income growth, especially in developing countries, cause the energy need increase.

In view of the distribution of power plants in Turkey and their effects of technologic, economic, socioeconomic and life quality, decision makers have to choose the best alternatives to accomplish their goals to decide which power plant will be built [2].

Mehmet Emin Baysal

mebaysal@gmail.com

Nazlı Ceren Çetin

nazliceren@hotmail.com

1 Department of Industrial Engineering, Selcuk University, Akademi qtr. Yeni İstanbul st. No: 365, 42130 Selcuklu, Konya, Turkey

2 Department of Industrial Engineering, Aksaray University, Adana Road E-90 Highway 7th km, 68100 Aksaray, Turkey
In this article, Fuzzy Analytic Hierarchy Process (AHP), which is one of the multiple criteria decision-making methods, was used. By considering environmental damage of power plants, capital costs, space requirement, their advantages and used technological development under the main criteria of social acceptance, the power plants in Turkey were ranked and an order of preference was composed. In addition, how many power plants should be built was determined with fuzzy-weighted goal programming method by considering Turkey's installed capacity, number of power plants, energy generation and targets of demands in 2023. The study consisted of an introduction, literature search, multiple criteria decision-making methods and an application. Analytic Hierarchy Process and goal programming that are multiple criteria decision-making methods and fuzzy conditions of these methods were described. Later, it continued with an application and the results were included.

\section{Literature search}

Kowalski et al. worked on determining economically best option for sustainable energy using multiple criteria decision-

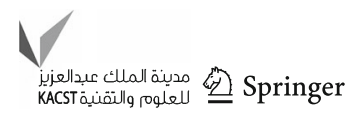


making methods for several gas emissions released by power plants. According to the results obtained, natural gas was determined as the best fuel [16]. Pilavachi et al. made a multiple criteria evaluation on nine types of power plants using hydrogen and natural gas as a fuel with AHP method under seven criteria. In this study, combined cycle plant with natural gas was determined as a better alternative [24]. While choosing the best alternative among renewable power plants in Turkey, Kahraman et al. used AHP method. At the end of the study, wind power plant was the best alternative for renewable energy [13]. Liu et al. evaluated the activities of thermal power plants between the years of 2004 and 2006 with respect to increasing electrical demands in Taiwan. According to the results obtained, combined cycle plants were determined as the most effective plants [20]. Shen et al. applied AHP method for determining economically and environmentally the energy value of investment selection for renewable energy resources within the frame of Taiwan Government's sustainable energy policies [29]. Kahraman and Kaya used fuzzy AHP method and VIKOR method to determine the choice of best alternative power plants for İstanbul [15]. Wang et al. applied AHP method for energy resources selection in China [32]. Lee et al. used fuzzy AHP in making a strategic route map of energy technologies to use alternative energy technologies against high oil prices [17]. Çebi et al. used fuzzy AHP and axiomatic design techniques for choosing the best alternative for investment and comparing renewable energy resources [14]. Jeberaj and Iniyan applied fuzzy AHP and AHP method for the choice of sustainable energy [11]. Liang et al. used the general fuzzy theory for energy planning, supply demand, assumption and renewable energy modeling. In the article, especially on the basis of the current situation, they improved a model for evaluating manufacturing projects about the usage of Analytic Hierarchy Process (AHP) and fuzzy evaluation. Later, while choosing manufacturing projects in China, a sample study for the evaluation of optimum manufacturing project showing the activity of the model was presented [18]. Anane et al. explained an innovator method to range the proper lands for watering using fuzzy AHP based on geographical information systems in the basin of TWW Nabeul-Hammamet (Tunisia) chosen as a target region [1]. Nixon et al. evaluated the main current collection of thermal solar energy technologies within the frame of AHP. These technologies were compared with technical, economic and environmental criteria [22]. Jinturkar and Deshmukh. Improved a fuzzy mixed-integer goal programming method for rural sintering and heating energy planning in the center of India [12]. Daim et al., improved a fuzzy goal programming in the state of Oregon to make a renewable portfolio giving an answer to $25 \%$ of energy demand obtained by renewable resources in 2025 [5]. San Cristobal applied a goal programming method for layout of five different renewable power plants in the region of Cantabria in Northern Spain by achieving seven targets about maintenance, management, investment, distances between power plants and energy generation [28]. Ramanathan and Ganesh used a goal programming model to ideally criticize seven energy resources used for lighting at twelve targets-driven houses representing energy, economic and environmental systems [26]. By considering financial and profit risks, Han et al. offered a multi-purpose optimization model for $\mathrm{CO}_{2}$ minimization infrastructure design and sustainable energy generation [7]. Chang recommended a multiple choice goal programming model to deal with the problem of capacity enhancement plan at the renewable energy sector [4]. Jayaraman et al. offered a goal programming model integrating plentiful allotments of labor resources to reach sustainable, economic, energy and environmental goals of United Arab Emirates [10].

\section{Multiple criteria decision making}

Multiple criteria decision making (MCDM), with the briefest definition, is a general name given for problem-solving of multiple and conflicted criteria to be achieved. MCDM explains a top-concept including designed techniques and methods to help people facing the problems being characterized by different size of criteria, and multiple and conflicted criteria [33]. The methods of MCDM are divided into two as multiple criteria and multi-objective. Multi-objective decision making is a model defined by the alternatives as a mathematic model. Multiple criteria decision making is an evaluation process using many criteria taking generally the value of different criteria and weighted, conflicted and even qualitative values on the purpose of eliminating, prioritizing, classifying, sorting and selecting a finite number of the options.

\section{Goal programming (GP)}

Goal programming was extended by Ijiri in the middle of 1960s, but it was improved by Ignizio and Lee in 1970s $[8,9]$. With a different viewpoint from linear programming, goal programming, instead of minimizing or maximizing an objective function, minimizes the deviations from the targets determined within the frame of current limitations. These deviations are shown as a negative deviation and a positive deviation. Since the ratio of these variables' objective functions is 0 , they cannot affect the results. Namely, the purpose of the problem in goal programming is to minimize the sum of variables showing the deviation [31]. In addition to this, goal programming combines multiple goals conflicting with decision maker's options. The targets determined in the results may not be reached, so even if there are no optimal results, the most acceptable ones can be obtained. In our article, a 
Table 1 Linguistic variables for weight/importance of decision makers and different goals

\begin{tabular}{ll}
\hline Linguistic variables & Triangle Fuzzy numbers \\
\hline Very low (VL) & $(0 \%, 5 \%, 10 \%)$ \\
Low (L) & $(5 \%, 10 \%, 25 \%)$ \\
Medium-low (ML) & $(20 \%, 32.5 \%, 45 \%)$ \\
Medium (M) & $(40 \%, 50 \%, 60 \%)$ \\
Medium-high (MH) & $(55 \%, 67.5 \%, 80 \%)$ \\
High (H) & $(75 \%, 85 \%, 95 \%)$ \\
Very high (VH) & $(90 \%, 100 \%, 100 \%)$ \\
\hline
\end{tabular}

preemptive goal programming model which is a variety of goal programming was used.

Preemptive GP formulation:

$\operatorname{Min} Z=\sum_{i=1}^{p} W_{\dot{\mathrm{I}}}^{+} \delta_{\dot{\mathrm{I}}}^{+}+W_{\dot{\mathrm{I}}}^{+} \delta_{\dot{\mathrm{I}}}^{-}$

s.t.

$f_{i}(x)+\delta_{\dot{\mathrm{I}}}^{+}-\delta_{\dot{\mathrm{I}}}^{-}=g_{i}, i=1 \cdots p$;

$x \in D$;

$\delta_{\dot{\mathrm{I}}}^{+}, \delta_{\dot{\mathrm{I}}}^{-} \geq 0, i=1 \cdots p$

$W_{\dot{\mathrm{I}}}^{-}$and $W_{\dot{\mathrm{I}}}^{+}$are priority values being associated with negative and positive deviations. The numerical value of the target achieved by decision maker is showed with $g_{i}$. The number of the targets determined by decision maker is showed with $p$. While being done an order of priority of a hierarchical structure by decision makers, Liou and Wang's Sorting Approach determining to reach different goals for fuzzy numbers was used here [19]. Linguistic variables are given for weight/importance of decision makers and different goals in Table 1.

As showed in Table, these linguistic variables are characterized by triangle fuzzy numbers. In the method of Liou and Wang's total integral value, $a \in[0,1]$ as an optimism index; for fuzzy numbers given as $(\tilde{A})=(a, b, c)$, total integral value is calculated in this way [19].

$$
\begin{aligned}
I_{T}^{a}(\tilde{A})= & a \mathrm{I}_{\mathrm{R}}(\tilde{A})+(1-a) I_{\mathrm{L}}(\tilde{A}) \\
= & a \int_{0}^{1} g_{\tilde{A}}^{\mathrm{R}}(y) \mathrm{d} y+(1-a) \int_{0}^{1} g_{\tilde{A}}^{\mathrm{L}}(y) \\
= & a \int_{0}^{1}[c+(b-c) y] d y \\
& +(1-a) \int_{0}^{1}[a+(b-a) y] \mathrm{d} y \\
= & \frac{1}{2}[a \cdot c+b+(1-a) a
\end{aligned}
$$

Suppose that $(\tilde{A}), d_{\tilde{A}}(x)$ is a triangle fuzzy number having membership function $d_{\tilde{A}}^{L}$ and $d_{\tilde{A}}^{R}$ are the right and left membership functions of the triangle fuzzy number. At last, the right and left integral values of $(\tilde{A})$ are defined as below.

$I_{L}(\tilde{A})=\int_{0}^{1} g_{\tilde{A}}^{L}(y) \mathrm{d} y$ and $I_{R}(\tilde{A})=\int_{0}^{1} g_{\tilde{A}}^{R}(y) \mathrm{d} y$

$g_{\tilde{A}}^{L}(y)$ ve $g_{\tilde{A}}^{R}(y)$, respectively, shows inverse functions of $d_{\tilde{A}}^{L}$ ve $d_{\tilde{A}}^{R}$. These inverse functions are formulated like the following equation.

$g_{\tilde{A}}^{L}(y)=a(b-a) y$ and $g_{\tilde{A}}^{R}(y)=c+(b-c) y$

While $y \in[0,1], a \in[0,1]$ as an optimistic index, the total integral value of $\tilde{A}$ is calculated below.

$$
\begin{aligned}
I_{\mathrm{T}}^{a}(\tilde{A}) & =a \mathrm{I}_{\mathrm{R}}(\tilde{A})+(1-a) I_{\mathrm{L}}(\tilde{A}) \\
& =\frac{1}{2}[a(b+c)+(1-a)(a+b)] \\
& =\frac{1}{2}[a c+b+(1-a) a]
\end{aligned}
$$

While $a=0$, the total integral value represents optimistic decision maker and it is calculated in the following equation.

$I_{T}^{0}(\tilde{A})=\frac{1}{2}[b+a]$

Total integral value of $a=0.5$ represents moderate decision maker and it is calculated in the following equation.

$I_{T}^{0.5}(\tilde{A})=\frac{1}{2}[0.5 c+b+0.5 a]$

Total integral value of $a=0.5$ represents optimistic decision maker and it is calculated in the following equation.

$I_{T}^{1}(\tilde{A})=\frac{1}{2}[c+b]$

$I_{\mathrm{T}}^{a}(\tilde{A})=a_{i k} i$ th for decision maker and $j$. for fuzzy goal are the performances [19].

\section{Analytic Hierarchy Process (AHP)}

AHP is a decision-making technique determining the order of importance by finding the priorities according to each other's criteria and making paired comparisons with objective and subjective criteria [30]. In these paired comparisons, it is preferred in terms of which one of them is more important than the other. By determining them, it is based on a numerical 
Table 2 Comparison matrix according to the weights given by decision makers

\begin{tabular}{llll}
\hline & 1st Decision maker & 2nd Decision maker & 3rd Decision maker \\
\hline Installed capacity increased & $\mathrm{MH}$ & $\mathrm{M}$ & $\mathrm{L}$ \\
Energy generation increased & $\mathrm{H}$ & $\mathrm{VH}$ & $\mathrm{M}$ \\
Power plants increased & $\mathrm{M}$ & $\mathrm{H}$ & $\mathrm{ML}$ \\
Power consumption increased & $\mathrm{VH}$ & $\mathrm{H}$ & $\mathrm{L}$ \\
$\mathrm{CO}_{2}$ emission decreased & $\mathrm{M}$ & $\mathrm{VH}$ & $\mathrm{VH}$ \\
\hline
\end{tabular}

\begin{tabular}{llll}
\hline & $\begin{array}{l}\text { 1st Decision maker } \\
\text { (moderate) (a) }\end{array}$ & $\begin{array}{l}\text { 2nd Decision } \\
\text { maker (optimistic) (b) }\end{array}$ & $\begin{array}{l}\text { 3rd Decision maker } \\
\text { (pessimistic) (c) }\end{array}$ \\
\hline $\begin{array}{l}\text { Installed capacity } \\
\text { increased }\end{array}$ & $0.55,67.5,80$ & $40,50,60$ & $5,15,25$ \\
$\begin{array}{c}\text { Energy generation } \\
\text { increased }\end{array}$ & $75,85,95$ & $90,100,100$ & $40,50,60$ \\
$\begin{array}{l}\text { Power plants } \\
\text { increased }\end{array}$ & $40,50,60$ & $75,85,95$ & $20,32.5,45$ \\
$\begin{array}{l}\text { Power consumption } \\
\text { increased }\end{array}$ & $90,100,100$ & $75,85,95$ & $5,15,25$ \\
$\begin{array}{c}\text { Installed capacity } \\
\text { increased }\end{array}$ & $0.55,67.5,80$ & $40,50,60$ & $5,15,25$ \\
$\begin{array}{c}\text { Energy generation } \\
\text { increased }\end{array}$ & $75,85,95$ & $90,100,100$ & $40,50,60$ \\
$\begin{array}{c}\text { Power plants } \\
\text { increased }\end{array}$ & $40,50,60$ & $75,85,95$ & $20,32.5,45$ \\
$\begin{array}{c}\text { Power consumption } \\
\text { increased }\end{array}$ & $90,100,100$ & $75,85,95$ & $5,15,25$ \\
$\begin{array}{c}\text { CO }{ }_{2} \text { emission } \\
\text { decreased }\end{array}$ & $40,50,60$ & $90,100,100$ & $90,100,100$ \\
\hline
\end{tabular}

Table 3 Fuzzy evaluation matrix for decision makers evaluation of them. AHP enables to make an order between options as well as determining the best option for a person who is about to make a decision. For the reason that this method which considers both quantitative and qualitative factors is used widely and is applied simply, it is applied easily even in the most complicated problems. In that being widely and flexible, AHP makes it a great convenient [6].

\section{Fuzzy Analytic Hierarchy Process (Fuzzy AHP)}

An enhanced fuzzy AHP method suggested by Chang was used in many problems, which fuzzy AHP was used. In this method, the cutting levels of "a" were not necessary. Besides using the values of artificial ratings, this method comes to the forefront with simple level sequencing and integrated sequencing. The most advantageous side of this method is that calculation requirement is low and it does not need any additional process by following the steps of classical AHP. The disadvantage of it is that it only uses fuzzy triangle numbers [6]. Pairwise comparisons matrices are arranged to determine the weights of criteria and these comparisons
Table 4 Fuzzy numbers used in criteria comparisons

\begin{tabular}{lll}
\hline Linguistic variable & Fuzzy values & Reciprocal values \\
\hline Equally important & $(1,1,1)$ & $(1 / 1,1 / 1,1 / 1 /)$ \\
Weakly important & $(1,3,5)$ & $(1 / 5,1 / 3,1)$ \\
Essentially important & $(3,5,7)$ & $(1 / 7,1 / 5,1 / 3)$ \\
Very strongly important & $(5,7,9)$ & $(1 / 9,1 / 7,1 / 5)$ \\
Absolutely important & $(7,9,11)$ & $(1 / 11,1 / 9,1 / 7)$ \\
\hline
\end{tabular}

will be made using fuzzy triangle numbers in Table 1. These fuzzy numbers were developed to be based on Saaty's 1-9 importance scale by Prakash [25,27] (Tables 2, 3, 4).

The Algorithm of Chang's fuzzy AHP where the disadvantages of traditional fuzzy AHP methods are not valid is used and calculations are made with the techniques of intersections of fuzzy numbers.

$\mathrm{X}$ composes the object cluster and $\mathrm{G}$ composes a target cluster. According to Chang's enlarged analysis method, $\mathrm{g}_{i}$ values were composed for each target. Thus, enlarged values of $m$ 's enlarged analysis for each object are below. 
$M_{g i}^{1}, \quad M_{g i}^{2}, \ldots, M_{g i}^{m}, \quad i=1,2, \ldots, n$

All values of $M_{g i}^{j}(j=1,2, \ldots m)$ given here are fuzzy numbers. The steps of Chang's enlarged analysis method are below;

Step 1 The value of fuzzy artificial size is defined according to the object $\mathrm{i}$.

$S_{i}=\sum_{j=1}^{m} M_{g i}^{j} \otimes\left[\sum_{i=1}^{n} \sum_{j=1}^{m} M_{g i}^{j}\right]^{-1}$

To obtain $\sum_{j=1}^{m} M_{g i}^{j}$, we carry on the addition on fuzzy numbers on $m$ values for a determined matrix;

$\sum_{j=1}^{m} M_{g i}^{j}=\left(\sum_{j=1}^{m} l_{j}, \sum_{j=1}^{m} m_{j}, \sum_{l_{j}}^{m} u_{j}\right)$

To obtain $\left[\sum_{j=1}^{n} \sum_{j=1}^{m} M_{g i}^{j}\right]^{-1}$, Fuzzy additions are made on the values of $M_{g i}^{j}(j=1,2, \ldots, m)$

$\sum_{\dot{\mathrm{I}}=1}^{n} \sum_{j=1}^{m} M_{g i}^{j}=\left(\sum_{i=1}^{n} l_{i}, \sum_{i=1}^{n} m_{i}, \sum_{l_{j}}^{n} u_{i}\right)$

And vector's reverse in the equation is calculated below.

$$
\left[\sum_{\mathrm{I}=1}^{n} \sum_{j=1}^{m} M_{g i}^{j}\right]^{-1}=\left(\frac{1}{\sum_{i=1}^{n} u_{i}}, \frac{1}{\sum_{i=1}^{n} m_{i}}, \frac{1}{\sum_{i=1}^{n} l_{i}}\right)
$$

Step $2 M_{1}=\left(l_{1}, m_{1}, u_{1}\right)$ and $M_{2}=\left(l_{2}, m_{2}, u_{2}\right)$ are two triangle fuzzy numbers.

The degree of probability is defined below;

$$
V\left(M_{2} \geq M_{1}\right)=\sup _{y \geq x}\left[\min \left(\mu_{M_{1}}(x), \mu_{M_{2}}(y)\right)\right]
$$

And expressed below.

$$
\begin{aligned}
V\left(M_{2} \geq M_{1}\right) & =\operatorname{hgt}\left(M_{1} \cap M_{2}\right)=\mu_{M_{2}}(d) \\
& = \begin{cases}1 & M_{2} \geq M_{1} \\
0 & l_{1} \geq u_{2} \\
\frac{l_{1}-u_{2}}{\left(m_{2}-u_{2}\right)-\left(m_{1}-l_{1}\right)} & \text { diğ }\end{cases}
\end{aligned}
$$

$V\left(M_{1} \geq M_{2}\right), M_{1}=\left(l_{1}, m_{1}, u_{1}\right)$ and $M_{2}=\left(l_{2}, m_{2}, u_{2}\right)$ are the ordinates of junction points of triangle fuzzy numbers. In other words, these are the values of membership the function. To compare $M_{1}$ and $M_{2}$, the values of both $V\left(M_{1} \geq M_{2}\right)$ and $V\left(M_{2} \geq M_{1}\right)$ are required to be found.

The intersection of triangle fuzzy numbers is given in Fig. 1

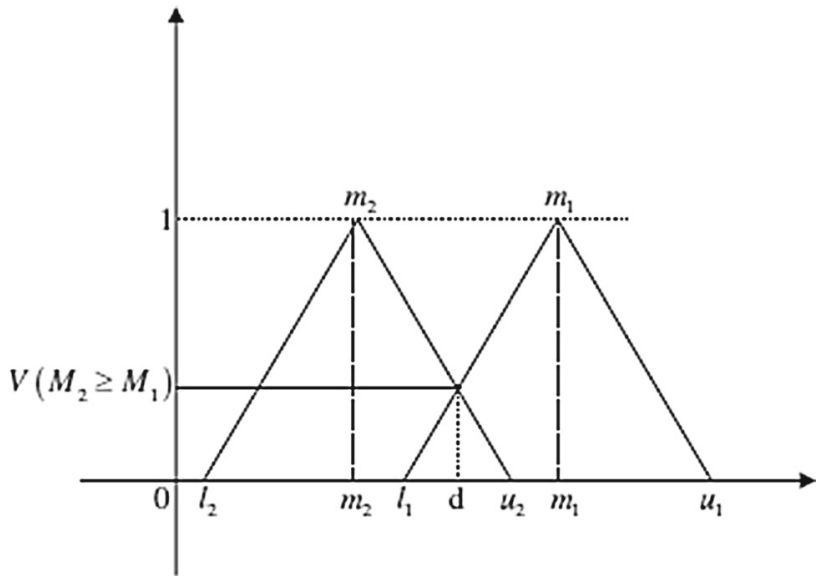

Fig. $1 M_{1}$ and $M_{2}$ the intersection of triangle fuzzy numbers [3]

Step 3 That the degree of probability of a convex fuzzy number is bigger than the convex number of $M_{\mathrm{I}}(I=1,2$, $\ldots, k)$ is defined below.

$$
\begin{aligned}
V & \left(M \geq M_{1}, M_{2}, \ldots, M_{k}\right) \\
& =V\left[\left(M \geq M_{1}\right) \text { and }\left(M \geq M_{2}\right) \text { and } \ldots \text { and }=\left(M \geq M_{k}\right)\right] \\
& =\min V\left(M \geq M_{i}\right), \quad i=1,2,3, \ldots, k
\end{aligned}
$$

For $k=1,2, \ldots, n ; k \neq i$, calculated as $d^{\prime \prime}$, the weighting vector is obtained below.

$W^{i}=\left(d^{\prime}\left(A_{1}\right), d^{\prime}\left(A_{2}\right), \ldots, d^{\prime}\left(A_{n}\right)\right)^{T}$

Here $A_{i}(i=1,2, \ldots, n)$ consists of the members.

Step 4 When normalizing the weighting vector given above,

$W=\left(d\left(A_{1}\right), d\left(A_{2}\right), \ldots, d\left(A_{n}\right)\right)^{T}$

The vector above is obtained. Now, this $\mathrm{W}$ weighting vector is not a fuzzy number [27].

\section{Application}

\section{The Preemptive Goal Programming application}

In our study, seven power plants were analyzed; $S_{1}$ as a coal plant, $S_{2}$ as a natural gas combined cycle power plant, $S_{3}$ as a hydropower plant, $S_{4}$ as wind plant, $S_{5}$ as a geothermal plant, $S_{6}$ as a solar plant and $S_{7}$ as a biomass plant were defined. Turkey's installed capacity, energy generation, energy demand and greenhouse gas emission defined as its sectorial indicators were divided into the numbers of power plants and the obtained values are given in Table 5 [21]. 
Table 5 Energy indicators

\begin{tabular}{llllll}
\hline Power plants & $\begin{array}{l}\text { The number of current } \\
\text { power plants }\end{array}$ & $\begin{array}{l}\text { Installed capacity/the } \\
\text { number of current } \\
\text { power plants }\end{array}$ & $\begin{array}{l}\text { Energy generation/ } \\
\text { the number of current } \\
\text { power plants }\end{array}$ & $\begin{array}{l}\text { Energy demand/the } \\
\text { number of current } \\
\text { power plants }\end{array}$ & $\begin{array}{l}\text { Greenhouse gas emission/ } \\
\text { the number } \\
\text { power plants }\end{array}$ \\
\hline coal & 38 & 0.423 & 2282.6 & 1.2 & 1.4 \\
Natural gas & 213 & 0.109 & 672.6 & 0.109 & 0.419 \\
Hydro & 562 & 0.047 & 124.7 & 0.106 & 0.0026 \\
Wind & 130 & 0.035 & 93.4 & 0.010 & 0.00066 \\
Geothermal & 22 & 0.029 & 158 & 0.0025 & 0.004 \\
Solar & 113 & 0.0036 & 5.28 & 0.067 & - \\
Biomass & 68 & 0.0049 & 23.69 & 0.012 & 0.00058 \\
\hline
\end{tabular}

It was calculated using (3.4), (3.5) and (3.6)'s priority values of goals and fuzzy evaluation matrix in Table 4 below.

$\frac{1}{2}[0.5 c+b+0.5 a]+\frac{1}{2}[c+b]+[b+a]$

Goal Programming Model:

Objective Function;

Min

$$
\begin{aligned}
& 0,441 d_{11}+0,441 d_{12}+0,766 d_{21}+0,766 d_{22} \\
& \quad+0,523 d_{31}+0,523 d_{32}+0,875 d_{41} \\
& \quad+0,875 d_{42}+0,816 d_{51}+0,816 d_{52}
\end{aligned}
$$

\section{Constraints;}

$$
\begin{aligned}
& 0,423 x_{1}+0,109 x_{2}+0,047 x_{3}+0,035 x_{4} \\
& +0,029 x_{5}+0,0036 x_{6}+0,0049 x_{7}+d_{11}-d_{12}=120 \\
& 2282,6 x_{1}+672,6 x_{2}+124,7 x_{3}+93,4 x_{4} \\
& +158 x_{5}+5,28 x_{6}+23,69 x_{7}+d_{21}-d_{22}=416000 \\
& 1,2 x_{1}+0,109 x_{2}+0,106 x_{3}+0,010 x_{4} \\
& +0,0025 x_{5}+0,067 x_{6}+0,012 x_{7}+d_{31}-d_{32}=218 \\
& x_{1}+x_{2}+x_{3}+x_{4}+x_{5}+x_{6}+x_{7}+d_{41}-d_{42}=2148 \\
& 1,4 x_{1}+0,419 x_{2}+0,0026 x_{3}+0,00066 x_{4} \\
& +0,004 x_{5}+0,00058 x_{7}+d_{51}-d_{52}=240 \\
& 0,423 x_{1} \geq 30 \\
& 0,109 x_{2} \geq 37 \\
& 0,047 x_{3} \geq 36 \\
& 0,035 x_{4} \geq 20 \\
& 0,029 x_{5} \geq 0,6 \\
& 0,0036 x_{6} \geq 3 \\
& x_{1} \geq 38 \\
& x_{2} \geq 213 \\
& x_{3} \geq 562
\end{aligned}
$$

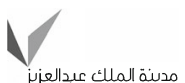

Table 6 Lindo outputs

\begin{tabular}{llll}
\hline Variable & Value & Variable & Value \\
\hline$x_{1}$ & 71,00000 & $d_{11}$ & 0,000000 \\
$x_{2}$ & 340,0000 & $d_{12}$ & 7,088600 \\
$x_{3}$ & 766,0000 & $d_{21}$ & 0,000000 \\
$x_{4}$ & 572,0000 & $d_{22}$ & 133184,0 \\
$x_{5}$ & 22,00000 & $d_{31}$ & 47,92500 \\
$x_{6}$ & 834,0000 & $d_{32}$ & 0,000000 \\
$x_{7}$ & 68,00000 & $d_{41}$ & 0,000000 \\
& & $d_{42}$ & 525,0000 \\
& & $d_{51}$ & 0,000000 \\
& & $d_{52}$ & 4,356560 \\
\hline
\end{tabular}

$x_{4} \geq 130$

$x_{5} \geq 22$

$x_{6} \geq 113$

$x_{7} \geq 68$

$x_{i} \geq 0$

$d_{i} \geq 0$

Priority values obtained were used in minimization row. The values obtained in Table 6 were used in constraints under 2023 targets and it was solved in Lindo Software. Lindo output is shown in Table 6.

According to the results, in view of the numbers of the available power plant, the power plants that are required to be built must have been the solar power plant with the unit 834 and wind power plant with the unit 572. The first goal shows that the deviation in $d_{12}$ stayed under the targeted installed capacity. $d_{22}$, i.e., high deviation value at energy generation, is shown that energy need will be increased in the long term until 2023. Non-renewable fossil resources cannot supply energy demands in the long term. According to 2023 targets, the deviation demand in $d_{32}$ will stay under 47,92500 toe (tone of oil equivalent). The deviation in fourth goal, $d_{42}$ 
Table 7 The pairwise comparison matrix among the criteria [23]

\begin{tabular}{llllll}
\hline Criteria & ED & IC & SR & PE & VP \\
\hline Environmental damage (ED) & $(1,1,1)$ & $(1 / 5,1 / 3,1)$ & $(5,7,9)$ & $(3,5,7)$ & $(1,3,5)$ \\
Investment cost (IC) & $(1,3,5)$ & $(1,1,1)$ & $(7,9,11)$ & $(3,5,7)$ & $(3,5,7)$ \\
Space requirement (SR) & $(1 / 9,1 / 7,1 / 5)$ & $(1 / 11,1 / 9,1 / 7)$ & $(1,1,1)$ & $(1,5)$ & $(1,1,1)$ \\
Provided employment (PE) & $(1 / 7,1 / 5,1 / 3)$ & $(1 / 7,1 / 5,1 / 3)$ & $(1 / 5,1 / 3,1)$ & $(1 / 7,1)$ \\
Visual pollution (VP) & $(1 / 5,1 / 3,1)$ & $(1 / 7,1 / 5,1 / 3)$ & $(1,3,5)$ & $(1,1,1)$ \\
\hline
\end{tabular}

Table 8 The synthesis values related to criteria

\begin{tabular}{llll}
\hline Criteria & 1 & $\mathrm{~m}$ & $\mathrm{u}$ \\
\hline SED & 0.117 & 0.295 & 0.665 \\
SIC & 0.190 & 0.420 & 0.890 \\
SSR & 0.030 & 0.080 & 0.210 \\
SPE & 0.060 & 0.120 & 0.280 \\
SVP & 0.030 & 0.090 & 0.220 \\
\hline
\end{tabular}

shows that the numbers of power plants are required to be increased 525 units. Finally, the deviation value in $d_{51}$ shows that greenhouse gas emission is deficient almost 4,356560 Tone- $\mathrm{CO}_{2} / \mathrm{Gwh}$ and these are needed to be reduced using renewable energy resources.

\section{Fuzzy AHP application}

After the application of project investment, according to the model results of available energy alternatives in Turkey, it was seen to make an investment in renewable energy resources. In the second stage, it was analyzed which renewable energy resources were made an investment on and it was ordered. The used power plants are below.

$$
\begin{aligned}
& \mathrm{S}_{1}: \text { Hydro } \\
& \mathrm{S}_{2}: \text { Wind } \\
& \mathrm{S}_{3}: \text { Geothermal } \\
& \mathrm{S}_{4}: \text { Solar } \\
& \mathrm{S}_{5}: \text { Biomass }
\end{aligned}
$$

To compare these power plants, at first, the vectors were determined. Later, the vectors were compared dynamically with a point scoring system obtained with an expert opinion working at department of energy. Here below, it was given the statement of fuzzy values of the pairwise comparisons matrix. The pairwise comparison matrix among the criteria is given in Table 7.

According to the matrix above, the synthesis value of each criterion was calculated. The Eq. (3.9) was used (Table 8).

Using the values obtained, the comparisons of fuzzy values were made with Eq. (3.14) and the values below were found.
Table 9 The membership function values according to pairwise comparisons of criteria

\begin{tabular}{llllll}
\hline V & SED & SIC & SSR & SPE & SVP \\
\hline SED & - & 0.79 & 1 & 1 & 1 \\
SIC & 1 & - & 1 & 1 & 1 \\
SSR & 0.3 & 0.06 & - & 0.79 & 0.95 \\
SPE & 0.48 & 0.23 & 1 & - & 1 \\
SVP & 0.33 & 0.08 & 1 & 0.84 & - \\
\hline
\end{tabular}

Table 10 The weights of alternatives for each criterion

\begin{tabular}{llllll}
\hline Criteria & ED & IC & SR & PE & VP \\
\hline Hydro & 0.244 & 0.311 & 0.423 & 0 & 0 \\
Wind & 0.381 & 0.338 & 0.017 & 0.104 & 0.581 \\
Geothermal & 0.068 & 0.017 & 0.309 & 0.313 & 0 \\
Solar & 0.091 & 0.196 & 0.237 & 0.336 & 0.419 \\
Biomass & 0.213 & 0.135 & 0.012 & 0.245 & 0 \\
\hline
\end{tabular}

To calculate the vector in Table 9, the minimum one of priority values related to the alternatives from the obtained values is taken.

Priority vector was given below.

$W=(0,06 ; 0,08 ; 0,23 ; 0,79 ; 1)$

When the result of the calculation of priority vector, the vector below is obtained.

$W^{\prime}=(0,365 ; 0,463 ; 0,027 ; 0,106 ; 0,037)$

After determining the weights belonging to the criteria, taking an expert opinion working at an energy company and verbalization of numeric data of criteria, pairwise comparisons of five power plants were made.

After all calculations, by making a matrix applied by multiplication the criteria weights and alternatives weights, and total superiority weights of alternatives are calculated. In Table 10, the weights of alternatives were shown according to each criterion. Main criteria weights are given in Table 11. Total superiority weights of alternatives are given in Table 12.

After determining evaluation results of alternatives under the criteria 5 , by making a multiplication value related to each criterion with the obtained values, the weights were 
Table 11 Criteria weights according to pairwise comparison matrix

\begin{tabular}{llllll}
\hline Criteria Weights & 0.365 & 0.463 & 0.027 & 0.106 & 0.037 \\
\hline
\end{tabular}

Table 12 Total superiority weights of alternatives

\begin{tabular}{ll}
\hline & Total superiority weights of alternatives \\
\hline Hydro & 0.244 \\
Wind & 0.327 \\
Geothermal & 0.072 \\
Solar & 0.179 \\
Biomass & 0.167 \\
\hline
\end{tabular}

calculated. So, total superiority weights were calculated. According to the values, the wind power plant was determined as the best plant to be made an investment on. Hydropower plant follows it as rank number 2 and solar power plant follows it as rank number 3 .

\section{The conclusion}

At the first stage of the application, using ranking approach for fuzzy numbers and the determined targets composing of a multi-objective mixed-integer programming model of the fossil power plants consumed most and renewable energy resources in Turkey, as a result comparisons made by decision makers, the priority values were calculated with Liou and Wang's total integral value method. In the research conducted, the target of energy demand has been the highest priority. Under the limitations composed using the data targeted in 2023, the model was solved with Lindo software. According to 2023 targets, the solar power plant is a plant which is required to be made an investment on according to the results obtained by Lindo software. The wind power plant followed it as rank number two.

In the other stage of the application, by taking an expert opinion working at the department of energy under the criteria of space requirement, provided employment, investment cost, environmental damage of power plants in Turkey, Saaty's fuzzy number approach was used. The pairwise comparisons for first criteria and for second power plants for each criterion were made. Later, according to Chang's grading analysis method, the priority values of alternatives were calculated. In the criteria, weights were obtained after calculating the priority vector. Investment cost having the highest ratio was the first criteria; as second, the environmental damage followed it. The wind power plant was determined as the most proper option. Hydropower plants and solar power plants followed it.

The study can be taken into account as an important resource for decision makers, but, in addition to these, a country's geopolitical position, inter-countries treaties, and financial status are considered for the decision of investment.

Open Access This article is distributed under the terms of the Creative Commons Attribution 4.0 International License (http://creativecomm ons.org/licenses/by/4.0/), which permits unrestricted use, distribution, and reproduction in any medium, provided you give appropriate credit to the original author(s) and the source, provide a link to the Creative Commons license, and indicate if changes were made.

\section{References}

1. Anane M, Bouziri L, Limam A, Jellali S (2012) Ranking suitable sites for irrigation with reclaimed water in the Nabeul-Hammamet region (Tunisia) using GIS and AHS-multicriteria decision analysis. Resour Conserv Recycl 65:36-46

2. Başar HB (2011) Enerji santrallerinin çok ölçütlü değerlendirilmesi. Yüksek Lisans Tezi Gazi Üniversitesi Fen Bilimleri Enstitüsü, Ankara

3. Chang DY (1996) Applications of the extent analysis method on fuzzy AHP. Eur J Oper Res 95:649-655

4. Chang N (2015) Changing industrial structure to reduce carbon dioxide emissions: a Chinese application. J Clean Prod 103:40-48

5. Daim TU, Kayakutlu G, Cowan K (2010) Developing Oregon's renewable energy portfolio using fuzzy goal programming model. Comput Indus Eng 59:786-793

6. Güner H (2005) Bulanık AHP ve bir işletme için tedarikçi seçimi problemine uygulanması. M.Sc. Thesis Pamukkale University, Denizli

7. Han JH, Ahn YC, Lee IB (2012) A multi-objective optimization model for sustainable electricity generation and $\mathrm{CO} 2$ mitigation (EGCM) infrastructure design considering economic profit and financial risk. Appl Energy 95:186-195

8. Ignizio JP (1978) A review of goal programming: a tool for multiobjective analysis. J Oper Res Soc 29:1109-1119

9. Ijiri Y (1965) Management goals and accounting for control. RandMcNally, Chicago

10. Jayaraman R, La Torre D, Malik T, Pearson YE (2015) Optimal workforce allocation for energy, economic and environmental sustainability in the United Arab Emirates: a goal programming approach. Energy Procedia 75:2999-3006

11. Jebaraj S, Iniyan S (2006) A review of energy models. Renew Sustain Energy Rev 10:281-311

12. Jinturkar AM, Deshmukh SS (2011) A fuzzy mixed integer goal programming approach for cooking and heating energy planning in rural India. Expert Syst Appl 38:11377-11381

13. Kahraman C, Kaya İ, Çebi S (2009) A comparative analysis for multiattribute selection among renewable energy alternatives using fuzzy axiomatic design and fuzzy analytic hierarchy process. Energy 34:1603-1616

14. Kahraman C, Çebi S, Kaya İ (2010) Selection among renewable energy alternatives using fuzzy axiomatic design: the case of Turkey. J Univer Comput Sci 16:82-102

15. Kaya T, Kahraman C (2010) Multicriteria renewable energy planning using an integrated fuzzy VIKOR \& AHS methodology: the case of Istanbul. Energy 35:2517-2527

16. Kowalski K, Stagl S, Madlener R, Omann I (2009) Sustainable energy futures: methodological challenges in combining scenarios and participatory multi-criteria analysis. Eur J Oper Res 197:10631074

17. Lee SK, Mogi G, Kim JW (2009) Decision support for prioritizing energy technologies against high oil prices: a fuzzy analytic hierarchy process approach. J Loss Prev Process Ind 22:915-920 
18. Liang Z, Yang K, Sun Y, Yuan J, Zhang H, Zhang Z (2006) Decision support for choice optimal power generation projects: fuzzy comprehensive evaluation model based on the electricity market. Energy Policy 34:3359-3364

19. Liou TS, Wang MJJ (1992) Ranking fuzzy numbers with integral value. Fuzzy Sets Syst 50:247-255

20. Liu CH, Lin SJ, Lewis C (2010) Evaluation of thermal power plant operational performance in Taiwan by data envelopment analysis. Energy Policy 38:1049-1058

21. Ministry of Energy and Natural Resources web pages in the Electricity. http://www.enerji.gov.tr/tr-TR/Sayfalar/Elektrik Accessed 15 June 2016

22. Nixon JD, Dey PK, Davies PA (2010) Which is the best solar thermal collection technology for electricity generation in north-west India? Evaluation of options using the analytical hierarchy process. Energy 35:5230-5240

23. Özcan EC (2013) Elektrik üretim planlamasında çok amaçlı optimizasyon yaklaşımı: Türkiye örneği. Ph.D. Dissertation Gazi Üniversitesi Fen Bilimleri Enstitüsü, Ankara

24. Pilavachi PA, Stephanidis SD, Pappas VA, Afgan NH (2009) Multicriteria evaluation of hydrogen and natural gas fuelled power plant technologies. Appl Therm Eng 29:2228-2234

25. Prakash T (2003) Land suitability analysis for agricultural crops: a fuzzy multicriteria decision-making approach, M.Sc. Theses International Institute for Geo-information Science and Earth Observation, Enschede

26. Ramanathan R, Ganesh LS (1995) Energy alternatives for lighting in households: an evaluation using an integrated goal programming-AHP model. Energy 20:63-72

27. Saaty TL (2008) Decision-making with the analytic hierarchy process. Int J Serv Sci 1:83-98
28. San Cristóbal JR (2012a) A goal programming model for the optimal mix and location of renewable energy plants in the north of Spain. Renew Sustain Energy Rev 16:4461-4464

29. Shen YC, Shen YC, Lin GTR, Yuan BJC, Li KP (2010) An assessment of exploiting renewable energy sources with concerns of policy and technology. Energy Policy 38:4604-4616

30. Şengül Ü, Eren M, Eslamian Shiraz S (2012) Bulanık AHP ile belediyelerin toplu taşıma araç seçimi. Erciyes Üniversitesi İ.İ.B.F. Dergisi 40:143-165

31. Tütek H, Gümüşoğlu Ş (2008) Sayısal yöntemler: yönetsel yaklaşım. Beta Basım Yayım, İzmir

32. Wang B, Kocaoglu DF, Daim TU, Yang J (2010) A decision model for energy resource selection in China. Energy Policy 38:7130 7141

33. Zionts S (1979) MCDM: if not a Roman numeral, then what? Interfaces 9:94-101

Publisher's Note Springer Nature remains neutral with regard to jurisdictional claims in published maps and institutional affiliations. 